\title{
Surface Thermodynamics and Extended DLVO Theory of Acidithiobacillus ferrooxidans Cells Adhesion on Pyrite and Chalcopyrite
}

\author{
A. Vilinska and K. Hanumantha Rao*
}

Division of Mineral Processing, Luleå University of Technology, SE-971 87 LULEA, Sweden

\begin{abstract}
The adhesion of Acidithiobacillus ferrooxidans bacterial cells have been assessed by following the thermodynamic and extended DLVO theoretical approaches. Surface potential, interfacial tension and contact angle parameters that are necessary for the calculation of free energy of adhesion have been determined experimentally. The Hamaker constant involved in the Lifshitz-van der Waals interaction energy has been estimated by microscopic and macroscopic methods.

The free energy of adhesion found to be negative on pyrite and chalcopyrite minerals indicating the adsorption of bacterial cells on these minerals. The potential energy diagrams of total interaction energy versus separation distance curves also illustrate the feasibility of bacterial cells adhesion except in a $\mathrm{pH}$ region where the bacterial species and minerals possess similar surface charge with high magnitude. The present theoretical analysis of bacterial adhesion on mineral surfaces found to be in good agreement with the experimental results and previous findings in the literature. Thus, the bacterial adhesion behavior on minerals can be judged and explained by considering the physico-chemical interaction forces.
\end{abstract}

Keywords: Acidithiobacillus ferrooxidans, sulfide mineral, adhesion, surface thermodynamics, extended DLVO theory.

\section{INTRODUCTION}

Conventionally, physico-chemical methods are used in mineral processing, but now-a-days, biological processing routes are sought to solve the problems associated with lean grade ores and where the traditional methods fail to separate the minerals from complex ores. Acidophilic sulfur or iron oxidizing bacteria are used in bio-hydrometallurgical operations of leaching and in biobeneficiation processes such as bioflotation and bioflocculation [1]. Bio-leaching processes of the extraction of metals from sulfide and oxide minerals have been developed during the years and have been adopted by certain industries. Compared to bio-leaching processes, bio-beneficiation processes are relatively new and are under intense investigation in recent years and most of the studies are so far confined to laboratory [2]. Since the bacteria adhere to mineral surface within few minutes and alter the surface properties that are essential in mineral beneficiation techniques, the microorganisms have formidable applications in flotation and flocculation processes. The adhesion of bacterial cells on mineral surface is essentially one of the most important aspects determining the success of either bioleaching or biobeneficiation processes. Selective bacterial adhesion on minerals is a crucial factor for selectively modifying the surfaces relevant to flotation and flocculation processes.

Microorganisms have a tremendous influence on their environment through the transfer of energy, charge, and materials across a complex mineral-solution interface. Natural phenomena driven by the bacteria-mineral interactions are incredibly diverse, including major environment and geochemical processes. Much of the impetus to study the

\footnotetext{
*Address correspondence to this author at the Division of Mineral Processing, Dept of Chemical Engineering and Geosciences, Luleå University of Technology, Luleå, Sweden; Tel: +46-920 491705; Fax: +46- 920 97364; E-mail: hanumantha.rao@ltu.se, hrao@1tu.se
}

mineral-bacteria interactions arises from the expected impact on many technological areas, including protection against bacterial infection and biofouling [3], and minerals bioprocessing comprising bioremediation of organic and inorganic contaminants [4], bio-leaching and bio-beneficiation processes [5]. Common to many of these processes, the adhesion of bacteria on mineral surfaces occurs and reacts with mineral-water interface. Some types of bacteria utilize minerals as the terminal electron acceptor in the respiratory cycle and others recover energy from minerals by the enzymatic oxidation. However, the specific mechanisms of adhesion and charge transfer reactions remain a subject of debate [68]. The charge transfer mechanisms can be direct involving the adhesion of bacteria to the surface of sulfide minerals inducing oxidative/reductive dissolution [9], indirect mechanism which is mediated by ferric ions [10] and cooperative mechanism including direct and indirect mechanisms [8]. Previous studies have shown that under most physiological conditions the bacterial cell surface carries a net negative charge $[1,11]$, while, along with electrostatic force, hydrophobic, entropic, acid-base, and van der Waals interactions and $\mathrm{H}$-bonding are important in bacterial adhesion on mineral surfaces $[12,13]$.

The cells adhesion is generally a function of biological properties (chemotaxis, specific surface site adhesion) [14] besides physico-chemical forces between the interacting phases. Taking into account only the physico-chemical forces, there are two main approaches to judge or predict the bacterial adhesion on mineral surfaces [15]:

- Thermodynamic approach

- Extended DLVO approach

\subsection{Thermodynamic Approach}

According to thermodynamics, a system spontaneously undergoes a change from state A to state B if the change is 
advancing towards a lower energy state. In case of mineralbacteria adhesion, allow that state A represents mineral particles and cells dispersed in liquid, while state B represents a new phase of bacteria adsorbed on mineral. Then the change from a dispersed to adhered state will be spontaneous only if the energetic state of the adhered system B is lower. Mathematically, the free energy of adhesion $\Delta G_{a d h}$ can be expressed by

$\Delta G_{a d h}=\gamma_{b s}-\gamma_{b l}-\gamma_{s l}$

where $\gamma$ represents interfacial free energies for different interfaces: bacteria-solid $\left(\gamma_{b s}\right)$, bacteria-liquid $\left(\gamma_{b l}\right)$ and solidliquid $\left(\gamma_{s l}\right)[16,17]$. Adhesion is energetically favoured only if $\Delta G_{a d h}$ is negative. For calculation of $\Delta G_{a d h}$, the free energy of adhesion was divided into two parts: Lifshitz van der Waals component and acid-base component.

$\Delta G_{a d h}=\Delta G_{a d h}{ }^{A B}+\Delta G_{a d h}{ }^{L W}$

Calculation according to LW-AB approach using the Lifshitz-van der Waals dispersive and acid-base components of surface energies is:

$$
\Delta G_{a d h}{ }^{L W}=-2\left(\sqrt{\gamma_{b v}{ }^{L W}}-\sqrt{\gamma_{l v}{ }^{L W}}\right)\left(\sqrt{\gamma_{s v}{ }^{L W}}-\sqrt{\gamma_{l v}{ }^{L W}}\right)
$$

and

$$
\begin{aligned}
& \Delta G_{a d h}{ }^{A B}=2\left(\sqrt{{\gamma_{b v}}^{+}}-\sqrt{\gamma_{s v}{ }^{+}}\right)\left(\sqrt{\gamma_{b v}{ }^{-}}-\sqrt{\gamma_{s v}{ }^{-}}\right) \\
& -2\left(\sqrt{\gamma_{b v}{ }^{+}}-\sqrt{\gamma_{l v}^{+}}\right)\left(\sqrt{\gamma_{b v}^{-}}-\sqrt{\gamma_{l v}^{-}}\right) \\
& -2\left(\sqrt{\gamma_{s v}{ }^{+}}-\sqrt{\gamma_{l v}+}\right)\left(\sqrt{\gamma_{s v}{ }^{-}}-\sqrt{\gamma_{l v}}\right)
\end{aligned}
$$

\subsection{Extended DLVO Approach}

Classical DLVO approach [18, 19] includes Lifshitz van der Waals (LW) interactions, and electrostatic interactions. LW forces are always attractive and strong at shorter distances between neutral stable molecules. Coulombic electrostatic interaction forces could be attractive or repulsive depending on the surface charge of interacting particles. Acidbase interactions were added later by van Oss [20] to involve the electron donating-accepting abilities of different materials. Thus microbial adhesion to solid surfaces can be described by a sum of van der Waals, electrostatic and acidbase forces as a function of separation distance.

$G^{\text {total }}=G^{L W}+G^{E L}+G^{A B}$

Calculation of these forces depends on the geometry of interacting phases and for sphere-sphere system, the following equations were used:

Lifshitz van der Waals interaction energy:

$G^{L W}=-\frac{A}{12}\left[\begin{array}{l}\frac{y}{x^{2}+x y+x}+\frac{y}{x^{2}+x y+x+y} \\ +2 \ln \left(\frac{x^{2}+x y+x}{x^{2}+x y+x+y}\right)\end{array}\right]\left(\frac{1}{1+1.77\left(\frac{2 \pi H}{\lambda}\right)}\right)$

Electrostatic interaction energy:

$G^{E L}=\frac{\pi \varepsilon a_{1} a_{2}\left(\zeta_{1}+\zeta_{2}\right)}{a_{1}+a_{2}}\left[\frac{2 \zeta_{1} \zeta_{2}}{\zeta_{1}+\zeta_{2}} \ln \frac{1+e^{-\kappa H}}{1-e^{-\kappa H}}+\ln \left(1-e^{-2 \kappa H}\right)\right]$
Acid-base interaction energy:

$G^{A B}=\pi a \lambda \Delta G_{a d h}{ }^{A B} e^{[(d o-H) / \lambda]}$

where $H$ - separation distance, $a$ - radius of solid particle, $\zeta$ - zeta-potential, $\kappa$-double layer thickness ${ }^{-1}, A$ - Hamaker constant, $d_{0}-$ minimum separation distance between 2 surfaces $(0.157 \mathrm{~nm}), \lambda$ - correlation length of molecules in liquid (0.6 nm) and $x=H /\left(a_{1}+a_{2}\right), y=a_{1} / a_{2}$

For interaction energy calculation, the parameters such as zeta potential, particle size radius, double layer thickness are known or measurable, while for calculation of Hamaker constant there are two different methods available. The Hamaker constant value that influences the Lifshitz-van der Waals interaction energy could be obtained by microscopic and macroscopic approaches [21, 22]. According to the first microscopic approach, the total interaction is assumed to be the sum of all interactions between the atom pairs. In the second macroscopic approach, the particles and the medium are considered as a continuous phases.

In the presence of a liquid medium, the van der Waals energy between the particles is different, and therefore the Hamaker constant must be replaced by an effective Hamaker constant. In case of two different particles 1 and 2 dispersed in a medium 3 , the effective Hamaker constant is calculated by:

$A_{123}=A_{12}+A_{33}-A_{13}-A_{23}$

$\mathrm{A}_{12}$ is regarded as a geometric mean of $A_{11}$ and $A_{22}$ :

$A_{12}=\left(A_{11} \cdot A_{22}\right)^{1 / 2}$

Then, $A_{123}=\left(A_{11}^{1 / 2}-A_{33}{ }^{1 / 2}\right)\left(A_{22}^{1 / 2}-A_{33}{ }^{1 / 2}\right)$

For calculation of individual Hamaker constants for solid surfaces, Fowkes [22] proposed the following equation:

$A_{11}=6 \pi r^{2} \gamma_{s}^{D}$

where $r$ represents the intermolecular distance and $\gamma_{s}^{D}$ represents the dispersive component of the surface energy of the solid. According to Fowkes, for water and systems with the volume which have nearly the same size, the value of $6 \pi r^{2}$ is equal to $1.44 \times 10^{-18} \mathrm{~m}^{2}$. From the calculation of individual Hamaker constants using the known values of dispersive component of surface energies, the effective Hamaker constant can be evaluated.

Another possible way of obtaining Hamaker constant is using Lifshitz-van der Waals component of free energy of adhesion $\Delta G_{a d h}{ }^{L W}$, which is obtained from the contact angle measurements. The effective Hamaker constant is then given by [22]:

$A=12 \pi d_{0}^{2} \Delta G_{a d h}{ }^{L W}$

\section{MATERIALS AND METHODOLOGY}

\subsection{Mineral Samples Preparation}

Pure mineral samples of chalcopyrite and pyrite were obtained from Gregory, Bottley \& Lloyd, UK. The samples were crushed and ground in agate mill. After grinding, the minerals were sorted by wet sieving to obtain suitable coarse size fraction for flotation and contact angle measurements ($106+38 \mu \mathrm{m})$ and a fine fraction of minus $38 \mu \mathrm{m}$. A portion of minus $38 \mu \mathrm{m}$ was further ground and a size fraction of -5 $\mu \mathrm{m}$ was obtained by a micron filter cloth sieving in ultra- 
sonic bath, which was used in zeta potential and adsorption measurements. The minerals were acid washed with $\mathrm{HCl}$ to clean the surface from the oxidation products and with ethanol to clean the surface from any organic compounds. The samples were dried and stored at $-10^{\circ} \mathrm{C}$ until use. The surface area was measured for both size fractions with BET method (Flowsorb II 2300) and determined to be 0.06 and $1.02 \mathrm{~m}^{2} / \mathrm{g}$ for coarse and fine fractions of pyrite and, 0.17 and $1.9 \mathrm{~m}^{2} / \mathrm{g}$ for coarse and fine size fractions of chalcopyrite, respectively.

\subsection{Bacterial Cultivation}

Bacterial cells of Acidithiobacillus ferrooxidans were cultured in $9 \mathrm{~K}$ medium with the following chemical composition: $44.5 \mathrm{~g} / \mathrm{l}$ of $\mathrm{FeSO}_{4} .7 \mathrm{H}_{2} \mathrm{O}, 3 \mathrm{~g} / \mathrm{l}\left(\mathrm{NH}_{4}\right)_{2} \mathrm{SO}_{4}, 0.5 \mathrm{~g} / \mathrm{l}$ $\mathrm{MgSO}_{4} .7 \mathrm{H}_{2} \mathrm{O}, 0.5 \mathrm{~g} / 1 \mathrm{~K}_{2} \mathrm{HPO}_{4}$ and $0.1 \mathrm{~g} / \mathrm{l} \mathrm{KCl}$.

The medium $\mathrm{pH}$ was maintained with $\mathrm{H}_{2} \mathrm{SO}_{4}$ at $\mathrm{pH}$ 2. All solutions were made with deionised (distilled) water and sterilized in autoclave at $125^{\circ} \mathrm{C}$ for 15 minutes and iron sulphate solution was prepared separately and filtered through Millipore filter, to remove all possible particles and cells. Sterilized Erlenmeyer flasks were filled with $200 \mathrm{ml}$ of medium solution and inoculated with $20 \mathrm{ml}$ of bacterial solution. The flasks were continuously shaken in an orbital shaker at $150 \mathrm{rpm}$ and at $30^{\circ} \mathrm{C}$. At different time intervals, the $\mathrm{pH}, \mathrm{Fe}^{+2}$ content and number of cells per $1 \mathrm{ml}$ of medium solution were measured for estimating and defining the bacterial growth in the solution. The $\mathrm{Fe}^{+2}$ ions were determined by volumetric titration method and the cell number was counted using a microscope in Neubauer counting chamber with a defined volume of each square.

The bacterial cells used were at the end of exponential growth phase. A $20 \mathrm{ml}$ of the solution is used as an inoculum for the next culture and the rest is filtered through Whatman filter paper to remove all the precipitates and finally through Millipore filter. The bacterial cell mass was washed with $\mathrm{pH}$ 2 water to remove all the trapped metal ions and metabolites. The cell mass so collected was used in the investigations.

\subsection{Adsorption Measurements}

The $-5 \mu \mathrm{m}$ size fractions of minerals were used for adsorption studies. Tests were performed at $\mathrm{pH} 2$, at temperature $23^{\circ} \mathrm{C}$, at constant solid-liquid ratio $(1: 100)$ and at varied initial cell concentrations of $10^{7}, 5 \times 10^{7}, 10^{8}, 5 \times 10^{8}, 10^{9}$ cells $/ \mathrm{ml}$. Cells and minerals were interacted together for 30 minutes by conditioning the suspension using a magnetic stirrer. After conditioning, the suspension was filtered to separate the solids and the bacterial cells remaining in the liquid phase were estimated by direct counting method.

\subsection{Zeta Potential Measurements}

Zeta potential measurements were made using ZetaCompact equipped with video and Zeta4 software. The software allows the direct reading of zeta-potential calculated from the electrophoretic mobilites using Smoluchowski equation. The result is a particle distribution diagram, from which the mean mobilities are recalculated to zeta-potential values. Pyrite and chalcopyrite of $-5 \mu \mathrm{m}$ particle size at a concentration of $0.025 \mathrm{~g} / 100 \mathrm{ml}$ was used. Ionic strength of $10^{-2} \mathrm{M}$ was maintained with $\mathrm{KNO}_{3}$. The solution $\mathrm{pH}$ was adjusted using $\mathrm{HNO}_{3}$ and $\mathrm{KOH}$. Solutions with a specified $\mathrm{pH}$ and constant ionic strength were prepared and then the mineral was added. After 30 minutes conditioning, the $\mathrm{pH}$ of the suspension was recorded again and regarded as the $\mathrm{pH}$ of the measurement.

Zeta potential measurements of bacterial cells were performed similarly. Initially, A. ferrooxidans collected cell mass was washed with deionised water solution of $\mathrm{pH} 2$ adjusted with $\mathrm{H}_{2} \mathrm{SO}_{4}$. Different bacterial concentrations were attempted and a cell population of $2.5 \times 10^{7}$ cells $/ \mathrm{ml}$ found to be suitable for the instrument and accordingly used.

\subsection{Contact Angle Measurements}

\section{Bacteria}

Precipitate-free cell solution was filtered through millipore filter paper using vacuum filtration to obtain a uniformly distributed cell layer on the whole area of filter paper. When filtered, the filter paper was placed on a Whatman filter paper for a short time to remove the excess moisture. After moisture removal, the filter paper is dry enough to mount on a microscope slide glass with a help of double sided adhesive tape. The samples were air-dried to remove the rest of water moisture and contact angles were measured while placing a drop of liquid on the bacterial lawn surface. The dynamic contact angle was recorded with Krüss Easy drop equipment and evaluated with Drop Shape analysis software. A drop of liquid is placed on a bacterial lawn flat surface with the help of a syringe and advancing angle is recorded on a CCD camera. Experimentally a bacterial surface of 600-700 layers thick found to be sufficient to obtain a stabilised contact angle. Each measurement was repeated 3 times and the arithmetic mean was considered as the final contact angle for a particular liquid.

\section{Minerals}

Contact angle on solid powders was determined by sorption measurements using Krüss Tensiometer K100 and Krüss LabDesk 3.1 software. The Washburn equation is used to measure the contact angle on powder samples. When a column of powder bed is in contact with liquid, the pores between the particles act like small capillaries and the rise of liquid is measurable. The rise of liquid is expressed by the Washburn equation:

$$
\frac{I^{2}}{t}=\frac{\gamma_{1} \cdot r \cdot \cos \theta}{2 \eta}
$$

where $I$ represents the mass of the liquid flow, $\gamma_{l}$ is the surface tension of liquid, $r$ is the capillary radius, $\eta$ is the liquid viscosity and $\theta$ is the advancing angle. Capillary radius $r$ could be replaced by capillary constant and can be determined by using a low energy wetting liquid (n-Hexane) that wets the solids completely. In this case, $\cos \theta$ equal to 1 and the capillary constant is thus determined.

Using the obtained capillary constant, the contact angles for other liquids were determined. Pyrite and chalcopyrite powder samples of $-106+38 \mu \mathrm{m}$ size fraction were used. A 1 $\mathrm{g}$ of mineral was placed into a glass sample tube and was carefully and equally packed each time. Each measurement was repeated at least 3 times and the results found to be reproducible within \pm 3 degrees deviation and a mean value was reported in the results. 


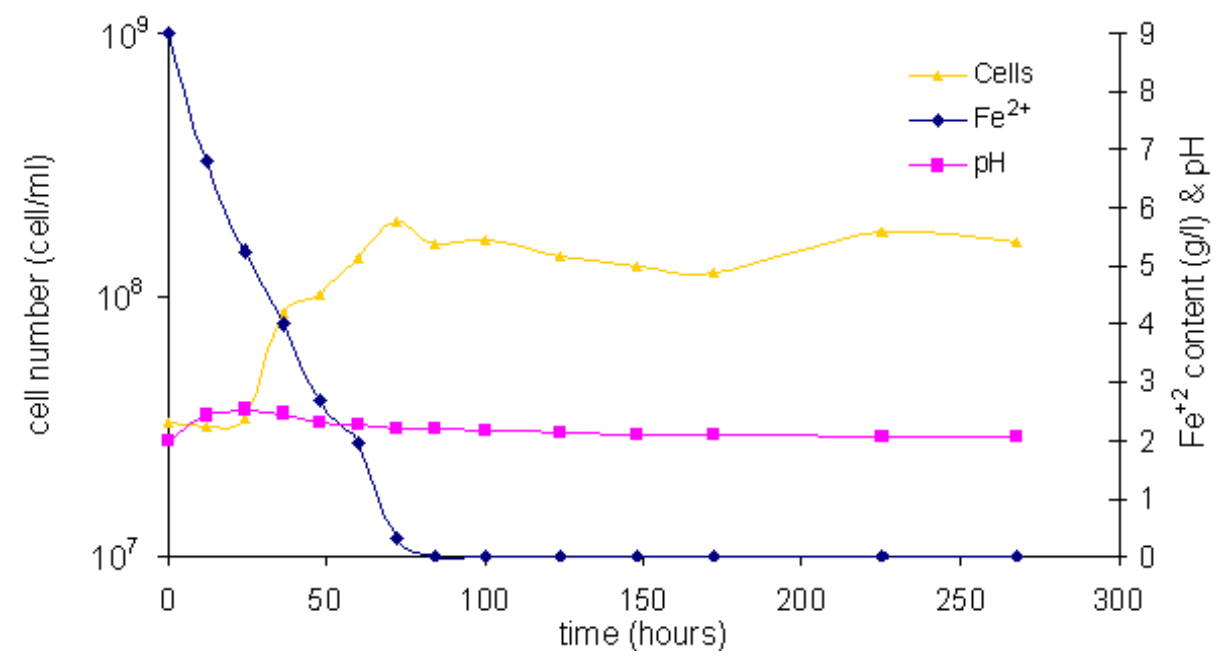

Fig. (1). Growth characteristics of A. ferrooxidans in $9 \mathrm{~K}$ medium.

For the estimation of acid and base surface energy components with van Oss method, contact angles of at least three different liquids with well characterized acid and base components are necessary. Four standard liquids of water, 1bromonaphtalene, diiodomethane and formamide were used. The values of liquids surface tension and the dispersive and polar part contributions to the surface energy, and the polar part divided into acid and base components of surface energy as reported in the literature were used [23, 24].

\section{RESULTS AND DISCUSSION}

\subsection{Bacterial Growth Characterisation}

The growth curve of A. ferrooxidans in 9K ferrous iron media is presented in Fig. (1). The cell number is increasing until the $\mathrm{Fe}^{2+}$ ions are completely oxidized and the medium with higher $\mathrm{Fe}^{2+}$ content is expected to produce liquor with higher amount of cell population. The $\mathrm{pH}$ of solution is relatively stable and only a slight increase is observable at the beginning due to consumption of $\mathrm{H}^{+}$by the cells, but after ferric hydroxide precipitation, it becomes constant around pH 2.

The decrease of $\mathrm{Fe}^{2+}$ ions with time is due to their bacterial oxidation to $\mathrm{Fe}^{3+}$ as follows:

$2 \mathrm{Fe}^{2+}+1 / 2 \mathrm{O}_{2}+2 \mathrm{H}^{+} \rightarrow 2 \mathrm{Fe}^{3+}+2 \mathrm{e}^{-}+\mathrm{H}_{2} \mathrm{O}$

$\mathrm{Fe}^{3+}$ is then abiotically hydrolyzed to $\mathrm{Fe}(\mathrm{OH})_{3}$, causing a recovery of $\mathrm{H}^{+}$ions:

$\mathrm{Fe}^{3+}+3 \mathrm{H}_{2} \mathrm{O} \rightarrow \mathrm{Fe}(\mathrm{OH})_{3}+3 \mathrm{H}^{+}$

Formation of colloidal precipitates was observed and the $\mathrm{Fe}^{3+}$ ions in the presence of sulphate and potassium ions can also cause jarosite $\mathrm{KFe}_{3}\left(\mathrm{SO}_{4}\right)_{2}(\mathrm{OH})_{6}$ formation [25].

\subsection{Adsorption Studies}

Adsorption isotherms of A. ferrooxidans on pyrite and chalcopyrite with respect to equilibrium cell concentration are presented in Fig. (2). Adsorption was found to be a fast

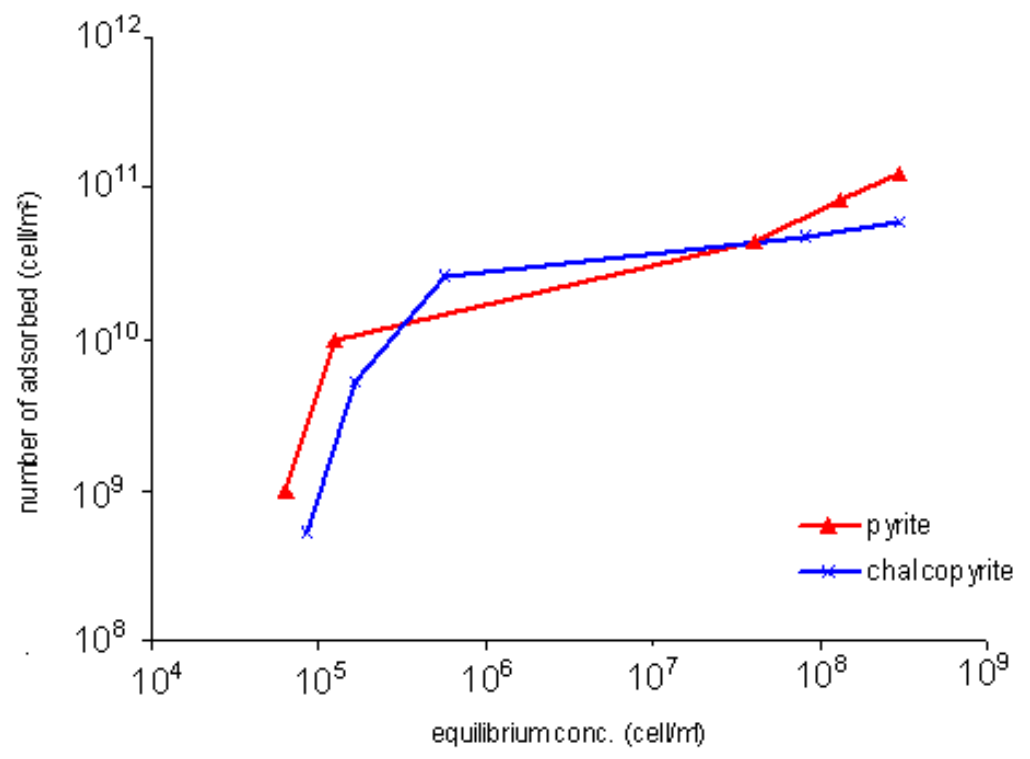

Fig. (2). Adsorption isotherm of A. ferrooxidans on pyrite and chalcopyrite. 
process onto both minerals and the isotherms show a saturation adsorption of about $10^{10}$ cells $/ \mathrm{m}^{2}$ at and above $10^{6}$ cells/ml concentrations. This adsorption density observed to be well below a full surface coverage in a horizontal orientation while considering the geometrical cell dimensions (i.e., length $\mathrm{x}$ breadth: $1.65 \times 0.35 \mu \mathrm{m})$. In the concentration range studied and at the highest equilibrium concentration, full surface coverage was not reached. The adherence of A. ferrooxidans cells is higher to pyrite compared with chalcopyrite. As previously reported [26], there are differences between the adhesion ability of different strains of the same acidophilic species toward pyrite and other sulphide minerals. The results in literature generally showed higher cells adhesion onto pyrite $[26,27]$. The adhesion is however dependent on thermodynamic balance of the mineral-bacteria system, surface charge of the particles and biological forces such as chemotaxis (directed move toward $\mathrm{Fe}^{2+}$ ) and preferential adsorption of cells to specific sites on mineral surface. For a better understanding, zeta potential and contact angle were determined so as to calculate the total interaction force according to extended DLVO approach pre-judging bacterial adhesion on mineral surfaces.

\subsection{Zeta-Potential}

The magnitude of surface charge of either positive or negative influences the adsorption process because of electrostatic force, which depends on the charges of interacting particles. Zeta-potential of A. ferrooxidans cells (Fig. 3) is almost constant in the whole $\mathrm{pH}$ range measured and displayed negative charge without exhibiting any iso-electric point (IEP).
The zeta potential curves of pure pyrite and chalcopyrite as a function of $\mathrm{pH}$ is similar, and both exhibited IEP around pH 7.5 (Fig. 3). Pure pyrite exhibited an IEP at pH 7.5 and above this $\mathrm{pH}$ the negative potential of the mineral increased with increasing $\mathrm{pH}$. The reported IEP of pyrite as determined by electrophoresis fall in between $\mathrm{pH} 3.5$ and $7.5[13,28$ $30]$, and this variation could arise from several factors such as origin-mineralogy, sample preparation, surface oxidation and aging in water. The IEP of chalcopyrite displayed at almost identical $\mathrm{pH}$ as pyrite, but the magnitude of surface charge is lower at acidic and basic $\mathrm{pH}$ values.

\subsection{Surface Energies of Cells and Minerals}

The liquid contact angles on mineral samples were determined by sorption measurements using the Washburn equation (Equation 14). Typical liquid sorption curves are presented in Fig. (4) as the square of liquid mass versus time. From the contact angle data presented in Table 1, it is clear that the surface of bacterial cells is more hydrophilic compared with minerals and after bacterial interaction, the surface hydrophobic character of minerals is reduced. The surface energies were calculated using van Oss acid-base approach to determine not only the dispersive and polar components of surface energies, but also to define the acid and base character of surfaces. Surface energies of solids and bacterial cells are comparable and fall in the range 42.39 to $53.75 \mathrm{mJm}^{-2}$. Surface energy of pyrite is higher compared to chalcopyrite and therefore, the dispersive and polar components of surface energy are also higher but they are proportional to chalcopyrite. Chalcopyrite displayed marginally

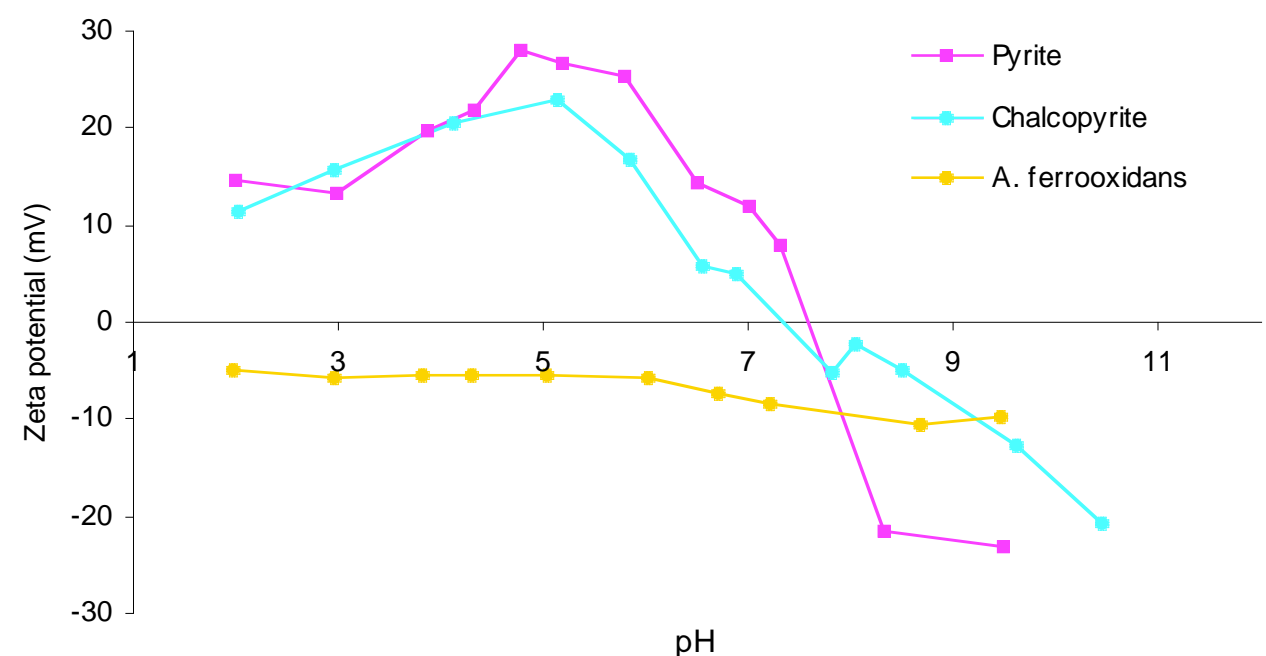

Fig. (3). Zeta potential of pyrite, chalcopyrite and A. ferrooxidans with respect to $\mathrm{pH}$.

Table 1. Contact Angles Data and Surface Energy Values Determined by Acid-Base Approach

\begin{tabular}{|c|c|c|c|c|c|c|c|c|c|}
\hline Material & \multicolumn{4}{|c|}{ Contact Angle $\theta$} & \multicolumn{5}{|c|}{ Surface Energy $\gamma\left(\mathbf{m} J . m^{-2}\right)$} \\
\hline Chalcopyrite & 71.76 & --- & 39.66 & 43.46 & 42.39 & 34.93 & 7.47 & 2.2 & 6.34 \\
\hline A. ferrooxidans & 33 & 53.5 & 36 & 32.5 & 48.55 & 34.31 & 14.24 & 1.11 & 45.57 \\
\hline
\end{tabular}




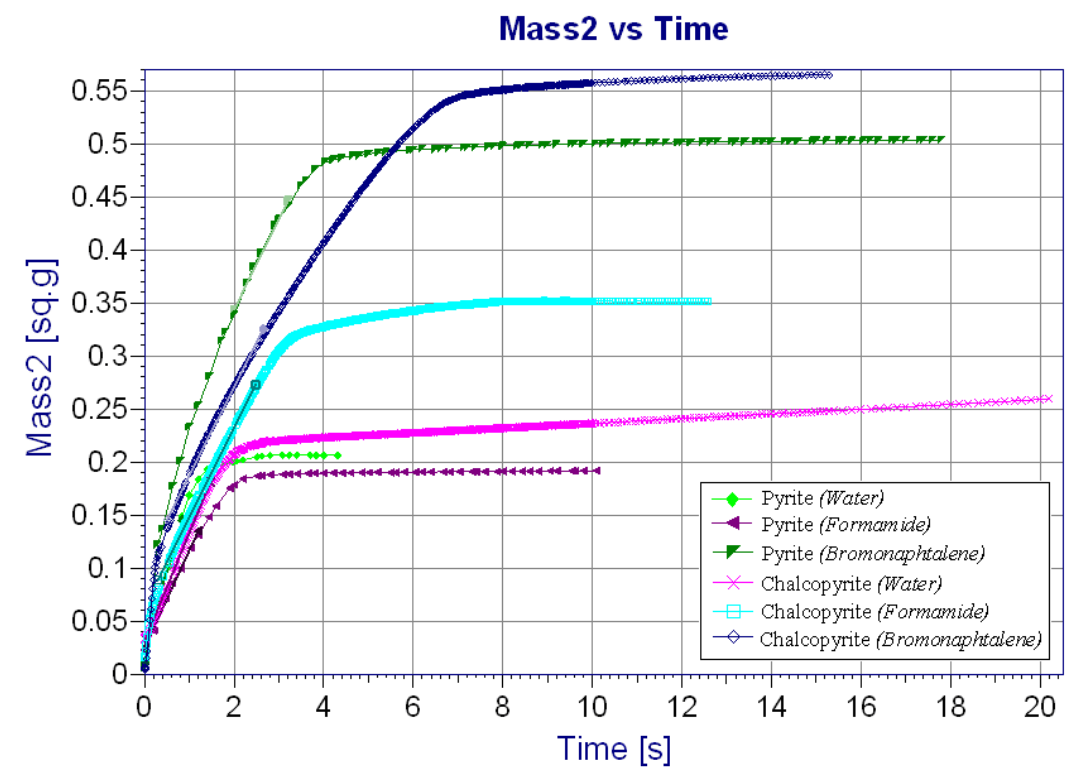

Fig. (4). Sorption curves of pyrite and chalcopyrite using different test liquids for contact angle estimation.

a higher electron donating character, because of higher $\gamma^{-}$ part and lower $\gamma^{+}$part compared with pyrite. The electron donating and accepting character is more balanced for pyrite. Surface energy of bacterial cells is within the range of minerals $\left(48.55 \mathrm{mJm}^{2}\right)$ but the dispersive and polar parts are different. Bacterial cells are more polar in nature than the minerals and this is due to their predominant surface functional groups. Electron donating character of cells is dominating with a much more higher value of $\gamma^{-}$than $\gamma^{+}$due to the occurrence of compounds containing - $\mathrm{OH}$ groups (sugars, carboxylic acids, lipids) characteristic of bacterial surface [31].

\subsection{Theoretical Approaches of Bacterial Cells Adhesion on Minerals}

\subsubsection{Thermodynamic Approach}

Free energy of adhesion computed by LW-AB approach for different mineral-bacteria cells are presented in Table 2. The Lifshitz-van der Waals component and acid-base component of free energy of adhesion is negative for all mineralbacteria systems and therefore the total free energy of adhesion is also negative. Thus the bacterial adhesion on minerals is energetically favourable and feasible. The higher electron acceptance ability of pyrite is responsible for the higher values of free energies of adhesion compared with chalcopyrite. The cells are strong electron donors and are attracted to an electron acceptor pyrite surface more. Combining all these factors, the attractive force between pyrite and A. ferrooxidans is stronger than between chalcopyrite and $A$. ferrooxidans.

Table 2. Free Energy of Adhesion

\begin{tabular}{|c|c|c|c|}
\hline & \multicolumn{3}{|c|}{ Free Energy of Adhesion $\Delta G_{\text {adh }}\left(\mathrm{mJ} \cdot \mathrm{m}^{-2}\right)$} \\
\hline & $\Delta \mathbf{G}_{\text {adh }}{ }^{L W}$ & $\Delta \mathbf{G}_{\text {adh }}{ }^{A B}$ & $\Delta \mathbf{G}_{\text {adh }}{ }^{\text {total }}$ \\
\hline Pyrite \& A. $f$. & -4.65 & -10.29 & -14.93 \\
\hline Chalcopyrite \& A.f. & -2.95 & -8.10 & -12.11 \\
\hline
\end{tabular}

Table 3. Calculated Hamaker Constants

\begin{tabular}{|c|c|c|c|c|c|}
\hline \multirow{2}{*}{} & Method 1 & \multicolumn{4}{|c|}{ Method 2 } \\
\cline { 2 - 6 } & $\mathbf{A 1}$ & $\mathbf{A}_{\mathbf{1 1}}$ & $\mathbf{A}_{\mathbf{2 2}}$ & $\mathbf{A}_{\mathbf{3 3}}$ & $\mathbf{A 2}$ \\
\cline { 2 - 6 } & \multicolumn{5}{|c|}{$\left[\mathbf{x 1 0} \mathbf{- 2 1}^{-21} \mathbf{J}\right.$} \\
\hline \hline Pyrite \& A.f. & 4.32 & 49.4 & 63.2 & 37 & 1.77 \\
\hline Chalcopyrite \& A.f. & 2.74 & 49.4 & 50.3 & 37 & 0.95 \\
\hline
\end{tabular}

\subsubsection{Extended DLVO Approach}

For calculation of interactive energy components of extended DLVO approach, the parameters such as Hamaker constant, surface potential and free energy of adhesion are essential and these parameters have been determined experimentally. Hamaker constants were calculated by two methods and the calculated values are presented in Table $\mathbf{3}$. Method 1 represents the calculation using LW part of free energy of adhesion in aqueous system and the effective Hamaker constant was obtained using Equation 13. Method 2 is based on calculating the effective Hamaker constant from the individual Hamaker constants for homogeneous phases. Hamaker constants for bacteria $A_{11}$ and mineral $A_{22}$ were estimated using the dispersive part of surface energies obtained from contact angle measurements and the water Hamaker constant $A_{33}$ was from the literature [32]. Hamaker constants calculated according to the methods 1 and 2 are of course different but the values are comparable and following the same trend. The Hamaker constant for pyrite - A. ferrooxidans system is higher than the chalcopyrite - A. ferrooxidans.

The sphere-sphere geometry of particles for calculating the interaction forces is the most suitable for mineralbacteria system, although the shape of bacillus cells is not exactly spherical. However considering the size of interacting bodies, the spherical model is reasonable. The energy is expressed in $\mathrm{kT}$ units in the interaction energy versus dis- 
tance diagrams presented in Figs. (5-9). For outlining the influence of various parameters, a model system was chosen with the following parameters: $\mathrm{pH} 2,0.01 \mathrm{M} \mathrm{KNO}_{3}$ electrolyte concentration, Hamaker constant estimated by Method 1 and $1 \mu \mathrm{m}$ size for particles and cells.

\section{Influence of Hamaker Constant}

Two different approaches were used for the Hamaker constant evaluation and as a result two different Hamaker constants were obtained for the same system. Lifshitz - van der Waals forces are always attractive, relatively weak and becoming significant at shorter separation distances. From Equation 6, it is clear that the LW interaction force is proportional to the value of Hamaker constant. The difference in the two Hamaker constants obtained by the methods 1 and 2 is rather small. It is also clear from Fig. (5) that the LW interactions, regardless of the value of Hamaker constant, are the weakest force in the total interaction energy between $A$. ferrooxidans and minerals. The Hamaker constant with either of the two values has no significant influence on the character of total interaction force. Hamaker constants obtained for pyrite- $A$. ferrooxidans system are higher and therefore the LW forces are higher compared with chalcopyrite- $A$. ferrooxidans. This is due to a higher electron acceptance character of pyrite (Table 1). The LW interactions have influence on total interaction energy, but the difference between the values determined by different methods is only few kT and is negligible compared with the strong attractive acid-base interactions. Regardless of the method used for Hamaker constant estimation, the adhesion of bacteria onto minerals is favorable. Due to a small difference between the calculated Hamaker constants by the two methods, only the value of $\mathrm{A} 1$ is used in further calculations.

\section{Influence of the Ionic Strength}

Ionic strength is inversely proportional to electrical double layer thickness surrounding the particle and increasing the ionic strength, the double layer compresses and zeta potential decreases. Equation 7 illustrates that the electrostatic force is a function of double layer thickness and zeta potential, and thus by increasing the ionic strength, the two parameters decrease leading to a drop in electrostatic force. Zeta potential was measured only at one electrolyte concentration; however potential energy diagrams were computed at varied ionic strength to identify its influence on bacterial adhesion behavior. Since the zeta-potential decreases with increasing ionic strength, the electrostatic force is greatly reduced for both systems (Fig. 6A). Strong long range attractive force can be achieved at low electrolyte concentration and the modeled $0.001 \mathrm{M}$ ionic strength led to an attractive force of $50 \mathrm{kT}$ at a distance of $10 \mathrm{~nm}(100 \AA)$ between pyrite and $A$. ferrooxidans. Depending on the magnitude of surface charge, electrostatic force can be strong or weak and therefore, a change in ionic strength displayed a great impact on the interaction forces (Fig. 6B, C). In the calculations, zeta potentials measured at $0.01 \mathrm{M} \mathrm{KNO}_{3}$ was only used and a change in zeta potential value due to a varied ionic strength was not incorporated and the calculations are rather simplified. In reality, zeta potential decreases with compressed double layer and the difference between different electrolyte concentrations are even more observable. Low electrolyte concentrations exaggerate the electrostatic force and they are preferable when the electrostatic force is weak, and higher concentrations are necessary to achieve fast adhesion or repulsion.

\section{Influence of Particle Size}

The size of bacterial cells is more or less the same (within one strain) and the mineral particles vary from submicron to $5 \mu \mathrm{m}$ size. The particle size was therefore varied in the simulation of interaction energy. Particle size is varied in the Lifshitz - van der Waals, electrostatic and acid-base interaction forces, while the bacterial size was kept constant due to its constant cell size. In the LW force calculation, the particle size is hidden in parameters $\mathrm{x}$ and $\mathrm{y}$ and a change from 1 to $4 \mu \mathrm{m}$ particle size had only a micro effect on the LW force. The curves at different particle sizes are overlapping as presented in Fig. (7A), and any difference in force is not observable. The effect of particle size within the tested and simulated conditions can be considered as negligible. On the other hand, the effect of particle size on electrostatic force is more distinguishable. From Equation 7, it is clear that the force is proportional to $a_{1} \cdot a_{2} /\left(a_{1}+a_{2}\right)$ and by keeping one parameter constant and increasing the another, the term is approaching 0 for very small values and 1 for high particle size. Using much higher particle size relative to the cells will increase the force only to some limit and using much smaller particles relative to cell size will minimize the electrostatic force. The simulated particle sizes were 1,2 and $4 \mu \mathrm{m}$ (Fig. 7) and with increasing particle size, the electrostatic force also increased and became significant at smaller separation distances. In the present model system, electrostatic force is attractive since the particle and bacteria are charged oppositely but the attractive force is not the strongest and the acid-base interactions are far the strongest. Therefore the alteration of particle size has not changed the electrostatic force and the total interaction energy markedly (Fig. 7C). However, the change is observable between bigger particles where the total attractive force is higher and this effect could be more predominant if the particles are charged more.

\section{Influence of $\mathrm{pH}$}

The $\mathrm{pH}$ of medium in which the particles are interacting is not a variable in the interaction equations but greatly influence the surface potential and therefore the electrostatic force of interaction. A. ferrooxidans cells are charged negatively in the entire $\mathrm{pH}$ range studied whereas the minerals charged positively below $\mathrm{pH} 7$ and negatively above this $\mathrm{pH}$ suggesting an attractive force at lower acidic $\mathrm{pH}$ values and repulsive force at alkaline $\mathrm{pH}$ values. Pyrite zeta potentials are higher in magnitude and accordingly the electrostatic force obtained for pyrite is higher compared with chalcopyrite. At $\mathrm{pH} 2$ and 7 the potentials are similar that resulted an

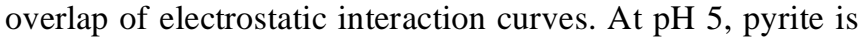
strongly positively charged, what resulted in strong electrostatic attraction towards cells and at $\mathrm{pH} 10$, the bacterial cells and minerals are repelling each other due to negative surface charges (Fig. 8). Based on lower surface charge characteristics of chalcopyrite compared to pyrite (Fig. 3), the electrostatic force for chalcopyrite is also lower (Fig. 9). The total

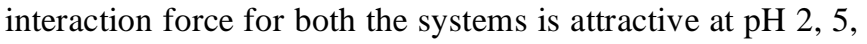
and 7 for all the separation distances while at $\mathrm{pH} 10$ only after approaching a distance of $2.7 \mathrm{~nm}(27 \AA)$ overcoming the energetic barrier. The adsorption tests were carried out at 

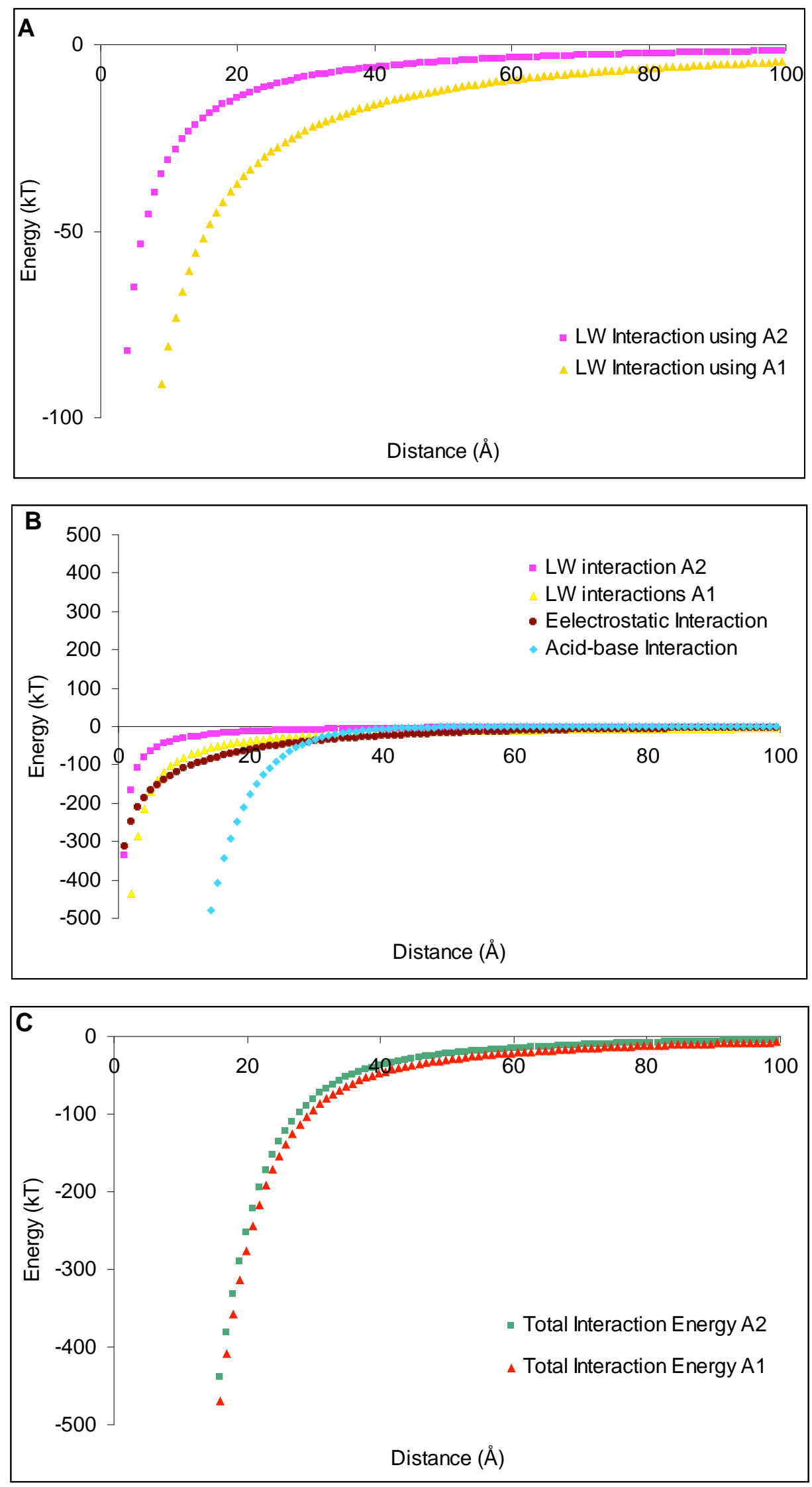

Fig. (5). Pyrite - A. ferrooxidans interaction energy diagrams at $\mathrm{pH} 2,0.01 \mathrm{M}$ ionic strength and $1 \mu \mathrm{m}$ particle size. LW forces calculated using Hamaker constants derived by Method 1 and Method 2 (A), with reference to other interactions (B) and their influence on the total interaction energies $(\mathbf{C})$. 

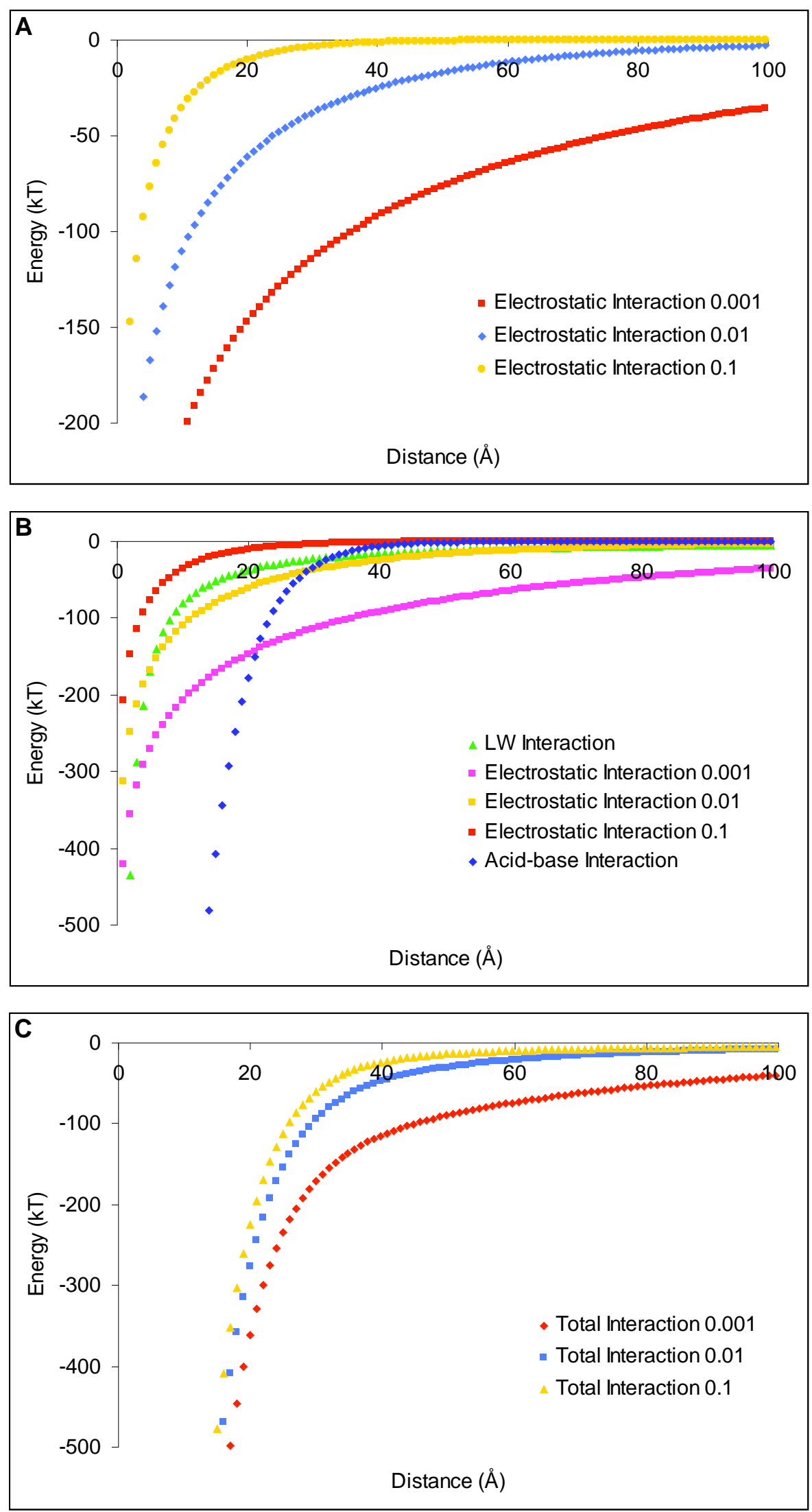

Fig. (6). Pyrite - A. ferrooxidans interaction energy diagrams at $\mathrm{pH} 2, \mathrm{LW}$ force calculated using $\mathrm{A}_{1}$ and $1 \mu \mathrm{m}$ particle size. Electrostatic interactions are presented at three different ionic strength $0.1 \mathrm{M}, 0.01 \mathrm{M}$ and $0.001 \mathrm{M} \mathrm{KNO}_{3}(\mathbf{A})$, with reference to other interactions $(\mathbf{B})$ and their influence on the total interaction energies $(\mathbf{C})$. 

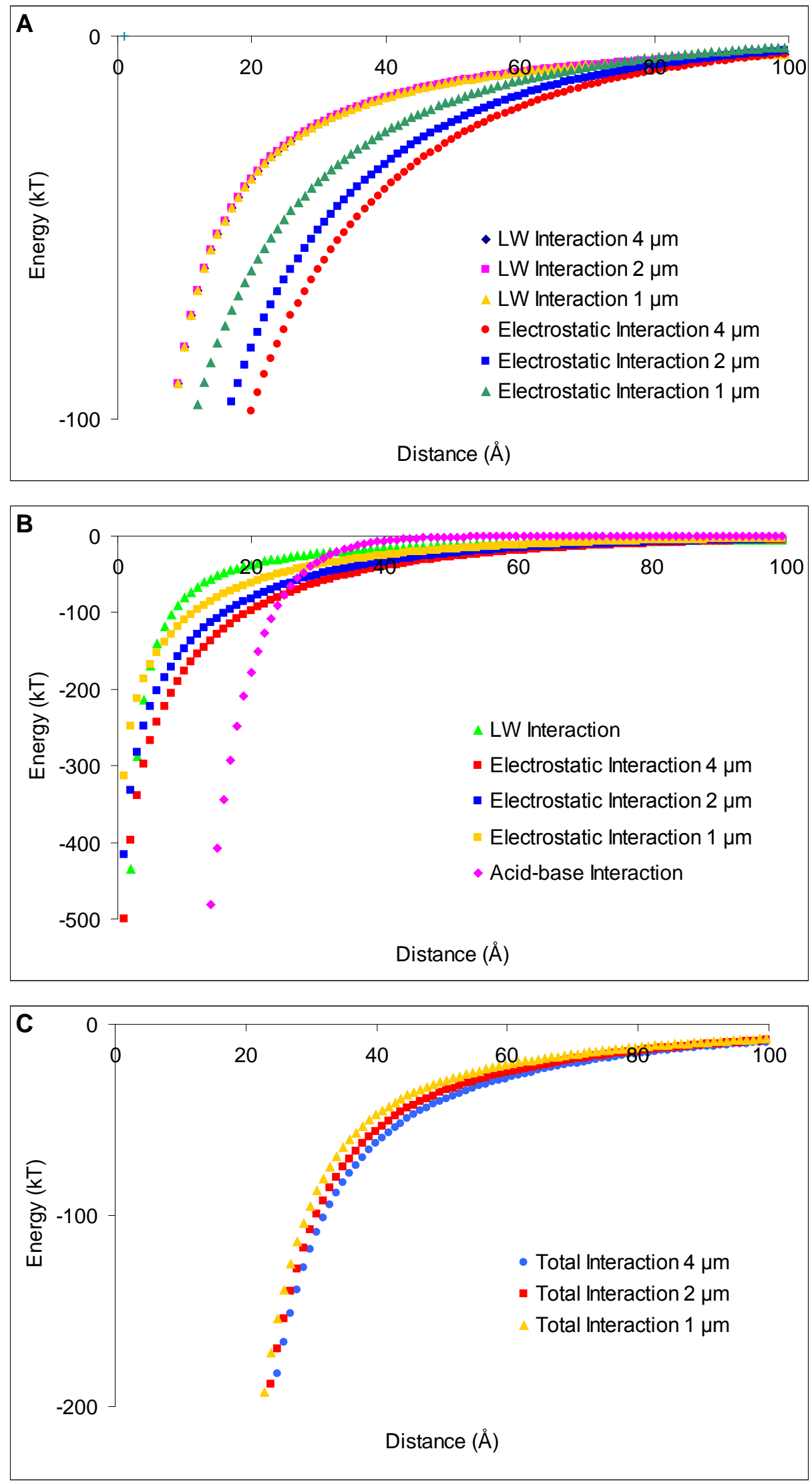

Fig. (7). Pyrite - A. ferrooxidans interaction energy diagrams at $\mathrm{pH} 2,0.01 \mathrm{M}$ ionic strength and $\mathrm{LW}$ force calculated using $\mathrm{A}_{1}$. Electrostatic and LW forces calculated using different particle sizes 1,2 and $4 \mu \mathrm{m}(\mathbf{A})$, with reference to other interactions $(\mathbf{B})$ and their influence on the total interaction energies $(\mathbf{C})$. 

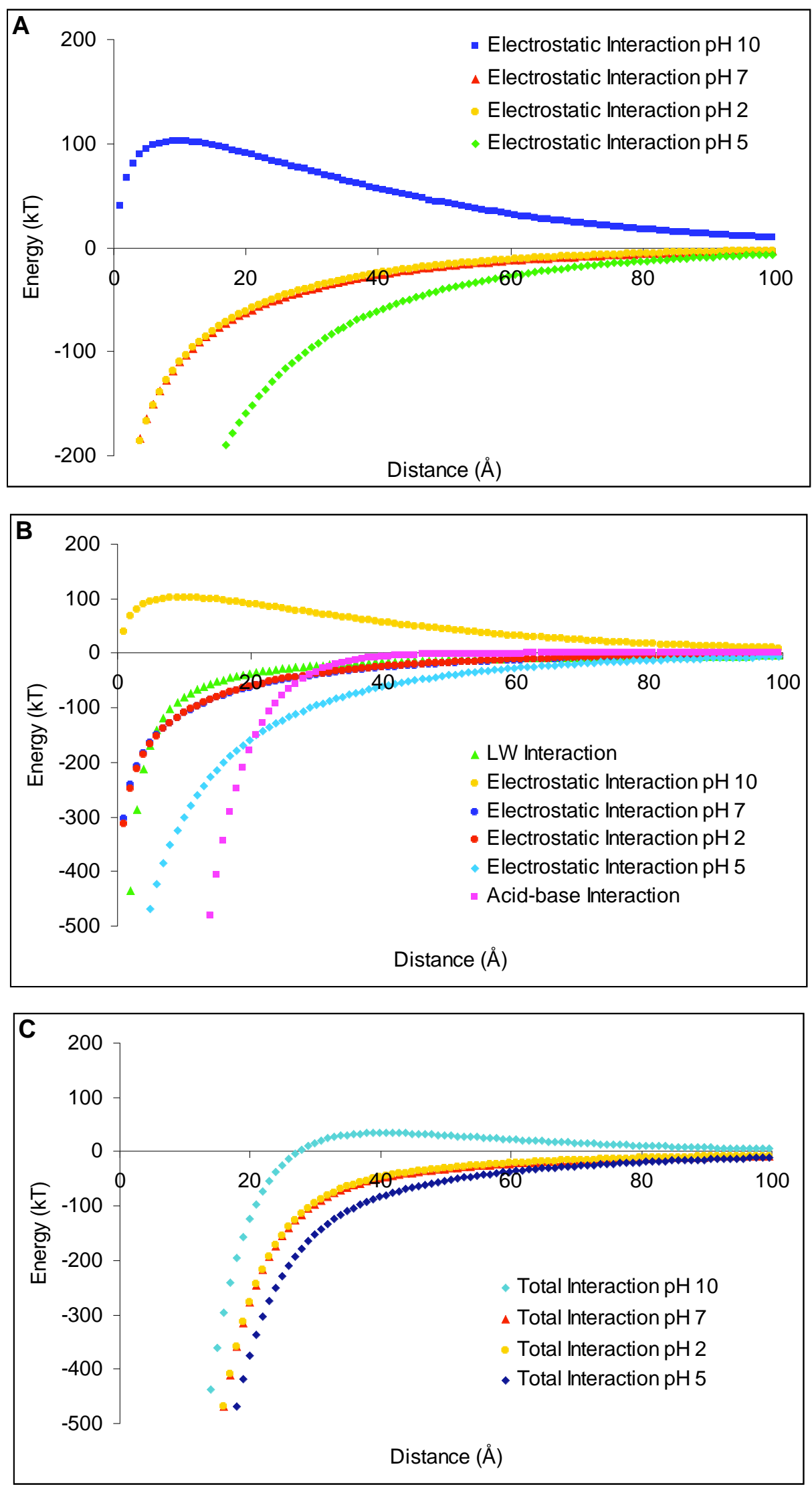

Fig. (8). Pyrite - A. ferrooxidans interaction energy diagrams at $0.01 \mathrm{M}$ ionic strength, $\mathrm{LW}$ force calculated using $\mathrm{A}_{1}$ and $1 \mu \mathrm{m}$ particle size.

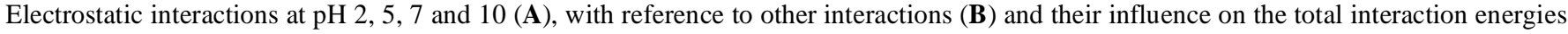
(C). 

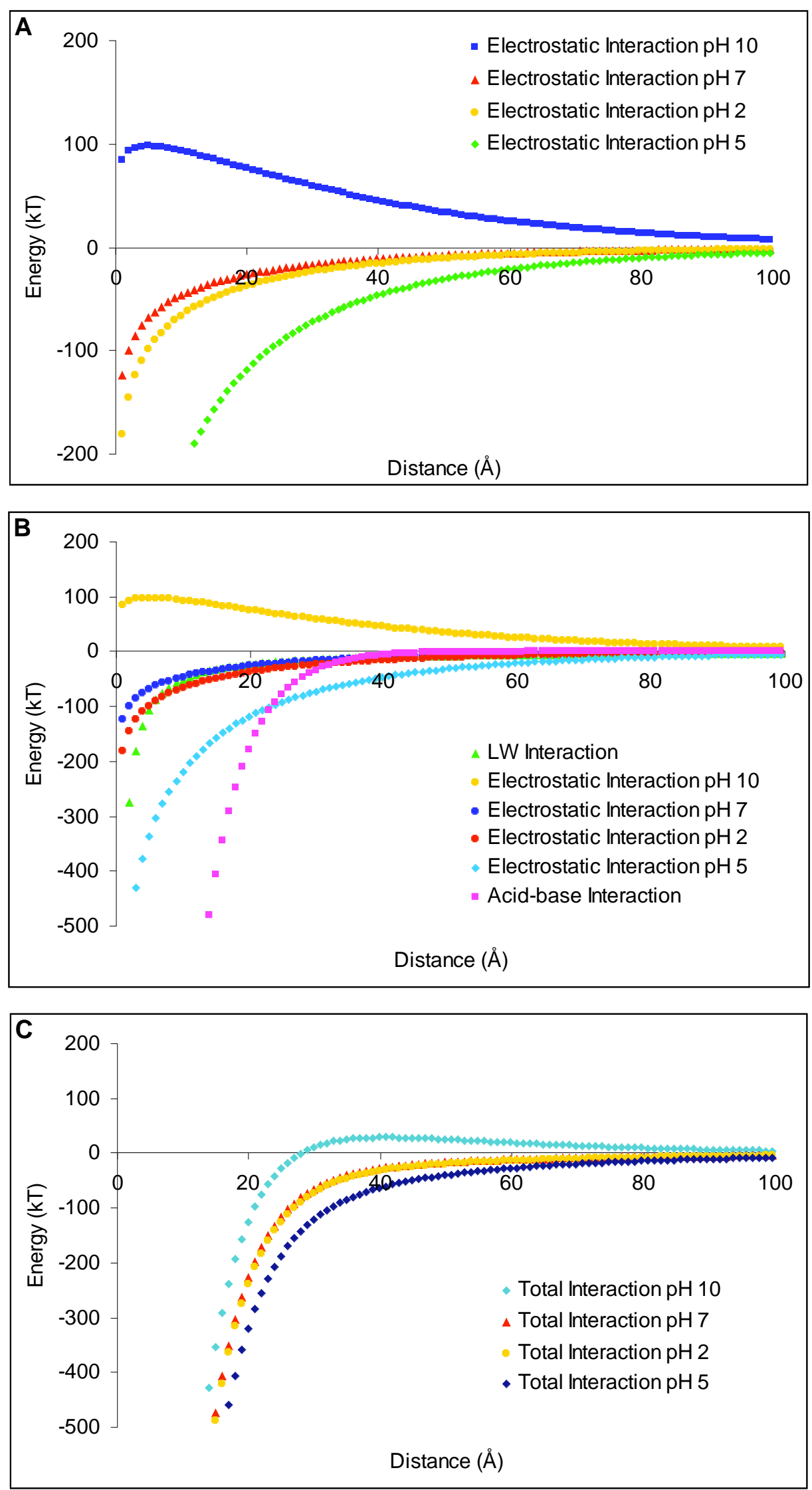

Fig. (9). Chalcopyrite - A. ferrooxidans interaction energy diagrams at $0.01 \mathrm{M}$ ionic strength, $\mathrm{LW}$ force calculated using $\mathrm{A}_{1}$ and $1 \mu \mathrm{m}$ particle size. Electrostatic interactions at $\mathrm{pH} \mathrm{2,5,7}$ and 10 (A), with reference to other interactions $(\mathbf{B})$ and their influence on the total interaction energies $(\mathbf{C})$. 
pH 2 and the total force is attractive for both the mineralbacteria systems. Because of higher acid-base and electrostatic interactions between the cells and pyrite, the adhesion of cells onto pyrite is more.

\section{Acid-Base Interactions}

Acid-base interactions depend on the acid and base surface energy component characteristics of the surfaces and it is a parameter in the calculation of acid-base component of free energy of adhesion. The acid-base part of free energy of adhesion is significantly negative for both mineral-bacteria systems because of different surface characteristics of cells and minerals. Cell surfaces are distinctively polar and strong electron donors, while the minerals possessed some electron acceptance ability. Acid-base interactions are the strongest and therefore are the decisive forces and attractive for both the systems. Because of higher electron accepting character of pyrite, the acid-base interaction energies are higher in this case and the cells adhesion onto pyrite is more preferred (Fig. 2).

\section{CONCLUSIONS}

The adhesion behavior of ferrous grown A. ferrooxidans cells onto pyrite and chalcopyrite is assessed by thermodynamic and extended DLVO theory approaches and verified experimentally. The influence of parameters involved in the physico-chemical interaction forces is verified and a favorable condition for cells adhesion onto minerals by varying these parameters is illustrated and discussed. For a stronger acid-base and weaker LW interaction systems, the influence of parameters on interaction energy is rather limited and difficult to alter the circumstances. The other significant force is the electrostatic. Modification of this force is possible through the variation of electrolyte concentration and $\mathrm{pH}$ where a change in surface potential occurs. In agreement with the adsorption studies, both the theoretical approaches yielded favorable condition of bacterial cells adhesion onto mineral surfaces. Experimentally determined differences between the adhesion of cells on pyrite and chalcopyrite were rather small and it was also the case in the computed interaction energy values, and in both cases the adhesion of cells onto pyrite was little higher. The selective adhesion necessary for bio-beneficiation processes could thus be achieved by changing the conditions influencing the electrostatic force. At $\mathrm{pH} 2$ of the natural growth condition of cells, the minerals have similar surface potentials but at a $\mathrm{pH}$ greater than 4.5 , the difference between the minerals is large manifesting higher electrostatic force between the cells and pyrite. At high alkaline $\mathrm{pH} \mathrm{10,} \mathrm{the} \mathrm{electrostatic} \mathrm{force} \mathrm{is} \mathrm{par-}$ tially repulsive and this $\mathrm{pH}$ is not conducive for physiological attributes of the cells. Manipulating the electrolyte concentration is influencing the electrostatic force proportionally for both the mineral-bacteria systems and additional $\mathrm{pH}$ change is necessary for selective cells adhesion onto pyrite. Another possible way to influence the bacterial adhesion is to change the surface properties of the bacteria itself by changing the conditions of growth. A. ferrooxidans cells grown in the presence of minerals secrete different amounts of extracellular polymeric substances thereby the surface properties and adhesion characteristics can be altered.

\section{ACKNOWLEDGEMENTS}

The financial support from the EU BioMinE project (contract no. IP NMP2-CT-2005-500329) is gratefully acknowledged.

\section{REFERENCES}

[1] Vilinska, A.; Hanumantha Rao, K.; Forssberg, E. Selective coagulation in chalcopyrite/pyrite mineral system using Acidithiobacillus group bacteria. Adv. Mater. Res., 2007, 20-21, 366-370.

[2] Vilinska, A.; Hanumantha Rao, K.; Forssberg, E. In: Wang, D.Z.; Sun, C.Y.; Wang, F.L.; Zhang, L.C.; Han, L.; Eds.; Microorganisms in Flotation and Flocculation of minerals - an overview. Proceedings of XXIV Internation mineral Processing Congress. Beijing, China, Science Press: Beijing, China, 2008; pp. 22-39.

[3] Gristina, A. G. Biomaterial centered infection: Microbial adhesion versus tissue integration. Science, 1987, 237, 1588-1595.

[4] Lovley, D.R. Anaerobes to the rescue. Science, 2001, 293, 14441446

[5] Sharma, P.K. Surface studies relevant to microbial adhesion and bioflotation of sulphide minerals. Doctoral thesis, Lulea University of Technology, Sweden, 2001

[6] Ehrlich H.C.; Brierley, C.L. Microbial Mineral Recovery, McGraw-Hill: New York, 1990.

[7] Sand, W.; Gerhke, T.; Jozsa, P.G.; Shippers, A. (Bio)chemistry of bacterial leaching - direct $v s$ indirect bioleaching. Hydrometallurgy, 2001, 59, 159-175.

[8] Tributsch, H. Direct versus indirect bioleaching. Hydrometallurgy, 2001, 59, 177-185.

[9] Schippers, A. Sand, W. Bacterial leaching of metal sulfides proceeds by two indirect mechanisms via thiosulfate or via polysulfides and sulfur. Appl. Environ. Microbiol., 1999, 65, 319-321.

[10] Schippers, A.; Jozsa, P.G.; Sand, W. Sulfur chemistry in bacterial leaching of pyrite. Appl. Environ. Microbiol., 1996, 62, 3424-3431.

[11] Sharma, P.K.; Das, A.; Hanumantha Rao, K.; Forssberg, K.S.E. Surface characterisation of Thiobacillus ferrooxidans cells grown under different conditions. Hydrometalurgy, 2003, 71, 285-292.

[12] Sharma, P.K.; Hanumantha Rao, K. Adhesion of Paenibacillus polymyxa on chalcopyrite and pyrite: surface thermodynamics and extended DLVO theory. Colloids Surf. B Biointerfaces, 2003, 29, 21-38

[13] Sharma, P.K.; Hanumantha Rao, K. Analysis of different approaches for evaluation of surface energy of microbial cells by contact angle goniometry. Adv. Colloid Interface Sci., 2002, 98, 341463.

[14] Rohwerder, T.; Gehrke, T.; Kinzler, K.; Sand, W. Bioleaching review part A: Progress in bioleaching: fundamentals and mechanisms of bacterial metal sulfide oxidation. Appl. Environ. Microbiol., 2003, 63, 239-248.

[15] Bos, R.; van der Mei, H.C.; Busscher, H.J. Physico-chemistry of initial microbial adhesive interactions - its mechanisms and methods for study. FEMS Microbiol. Rev., 1999, 23 (2), 179-230.

[16] Absolom, D.R.; Lamberti, F.V.; Policova, Z.; Zingg, W.; van Oss, C.J.; Neumann, A.W. Surface thermodynamics of bacterial adhesion. Appl. Environ. Microbiol., 1983, 46, 90-97.

[17] Busscher, H.J.; Weerkamp, A.H.; van der Mei, H.C.; van Pelt, A W.; de Jong, H.P.; Arends, J. Measurement of the surface free energy of bacterial cell surfaces and its relevance for adhesion. Appl. Environ. Microbiol., 1984, 48, 980-983.

[18] Deryagin, B.V.; Landau, L. Bacteria sulfide mineral interactions with reference to flotation and flocculation. Acta Physicochem., URSS, 1941, 55, 333.

[19] Verwey, E.J.; Overbeek, J.T.G. Theory of the stability of lyophobic colloids. J. Colloid Sci., 1955, 10, 224-225.

[20] Van Oss, C.J.; Good, R.J.; Chaudhury, M.K. The role of van der Waals forces and hydrogen bonds in "hydrophobic interactions" between biopolymers and low energy surfaces. J. Colloid Interface Sci., 1986, 111, 378-390.

[21] Van Oss, C.J.; Chaudhury, M.K.; Godd, R.J. Monopolar surfaces. Adv. Colloid Interface Sci., 1987, 28, 35-64.

[22] Fowkes, F.M. Attractive forces at interfaces. Ind. Eng. Chem., 1964, 56, 40-52. 
[23] Bellon-Fontaine, M.N.; Mozes, N.; Van Der Mei, H.C.; Sjollema, O. A comparison of thermodynamic approaches to predict the adhesion of dairy microorganisms to solid substrata. Cell Biophys., 1990, 17, 93-106.

[24] Ström, G.; Frederiksson, M.; Stenius, P. Contact angles, work of adhesion and interfacial tensions at a dissolving hydrocarbon surface. J. Colloid Interface Sci., 1987, 119, 352-361.

[25] Herbert, R.B. Properties of goethite and jarosite precipitated from acidic groundwater, Dalarna, Sweden. Clay. Clay Miner., 1997, 45, 261-273.

[26] Harneit, K.; Göksel, A.; Kock, D.; Klock, J.H.; Gehrke, T.; Sand, W. Adhesion to metal sulfide surfaces by cells of Acidithiobacillus ferrooxidans, Acidithiobacillus thiooxidans and Leptospirillum ferrooxidans. Hydrometallurgy, 2006, 83, 245-254.

[27] Sharma, P.K.; Das, A.; Hanumantha Rao, K.; Forssberg, K.S.E. In: Parekh, B.K.; Miller, J.D.; Eds.; Thiobacillus ferrooxidans interaction with sulfide minerals and selective chalcopyrite flotation from pyrite. Advances in Flotation Technology, Denver, Colorado, USA, SME, NY, USA, 1999; pp. 147-165.
[28] Das, A.; Hanumantha Rao, K.; Sharma, P.K.; Natarajan, K.A.; Forssberg, K.S.E. In: Amils, R.; Ballester, A., Eds.; Surface chemical and adsorption studies using Thiobacillus ferrooxidans with reference to bacterial adhesion to sulfide minerals, Biohydrometalurgy and the Environment toward the mining of the 21st Century, part A, IBS-1999; Madrid, Spain; Elsevier, 1999; pp. 697-707.

[29] Chandraprabha, M.N.; Natarajan, K.A.; Somasundaran, P: Selective separation of pyrite from chalcopyrite and arsenopyrite by biomodulation using Acidithiobacillus ferrooxidans. Int. J. Miner. Process., 2005, 75, 113-122.

[30] Natarajan, K.A.; Das, A: Surface chemical studies on Acidithiobacillus group of bacteria with reference to mineral flocculation. Int J. Miner. Process., 2003, 72, 189-198.

[31] Gehrke, T.; Hallmann, R.; Kinzler, K.; Sand, W. Importance of extracellular polymeric substances from Thiobacillus ferooxidans for bioleaching. Appl. Environ. Microbiol., 1998, 64, 2743-2747.

[32] Evans, D.F.; Wennerström, H. The colloidal domain where physics, chemistry, biology and technology meet. Wiley-VCH, 1994.

(c) Vilinska and Rao; Licensee Bentham Open.

This is an open access article licensed under the terms of the Creative Commons Attribution Non-Commercial License (http: //creativecommons.org/licenses/by$\mathrm{nc} / 3.0 /$ ) which permits unrestricted, non-commercial use, distribution and reproduction in any medium, provided the work is properly cited. 